\title{
STUDIES ON PROCESS IMPROVEMENT IN A BISCUIT MANUFACTURING INDUSTRY USING DMAIC APPROACH
}

\author{
Mohamed Shihab, Prashanth Reddy, Gaurav Prabhu, Risha Patil, Nandini B \\ Department of Industrial Engineering \& Management, R. V. College of Engineering, Mysore Road, \\ Bengaluru-560059, INDIA
}

\begin{abstract}
Process improvement studies were carried out in Paramount Nutrition Pvt. Ltd. located in Bidadi, Bengaluru, India. Paramount Nutrition Pvt. Ltd. is a contract manufacturer for $\mathrm{M} / \mathrm{s}$ Britannia and produces six variants of their biscuits. Our work and analysis is focused on a single-line of manufacturing and packing which produces two of the variants viz Good day butter and Good day cashew $\&$ almond biscuits. The present work is started by understanding the working facility at the manufacturing unit; and we, then followed a structured methodology to understand the problems which are present and find out ways of countering these problems. For our study, Define, measure, analyze, improve and control (DMAIC) approach was chosen. During the measure phase, it was seen that, packaging defects account to about $27.3 \%$ of the overall defects. After the detailed study, suggestions for improvement were given to reduce the packaging defects in the unit along with the reduction in the manufacturing defects. The process $\sigma$-levels for defects in packaging and manufacturing are calculated, followed by providing monthly goals to the manufacturer for reducing the defect rate each month in order to attain a $5 \sigma$ level by the end of $7^{\text {th }}$ month.
\end{abstract}

Keywords- Biscuits, DMAIC, 5o level, Packaging defects Manufacturing defects.

\section{INTRODUCTION}

Paramount Nutrition Pvt. Ltd., is a biscuit manufacturing facility located in Bidadi, Bangaluru, Karnataka State, INDIA. Paramount Nutrition Pvt. Ltd., are contract manufacturers for a big player in this market M/s Britannia. As Paramount Nutrition Pvt. Ltd., fall under the food processing sector, the standards and level of sanity should be maintained at a very high level. The facility runs $16 \mathrm{~h} \times 7$ days (in two shifts) a week to meet the targets set by M/s Britannia, which can be linked to the high demand levels that the company faces. The facility consists of two production lines which produce a total of 6 variants of biscuits. Our work, however, is focused on Line 1 which produces two variants viz Good day butter and
Good day cashew \& almond biscuits. A thorough research was carried out in the manufacturing unit to understand the processes involved, followed by collecting the required downtime and defects data. It was seen that, the Form (a chart) which was used to record the downtime lacked the structure, hence, a new Form was introduced to record the important downtime details such as: 1). Reason for downtime; 2). Duration of downtime; 3). Possible production loss due to downtime (in $\mathrm{Kg}$ ). The data recorded using the proposed Form is then collected and analyzed along with the defects data to observe and pinpoint a particular problem if it prevails. In the present study, DMAIC approach is adopted and this step by step approach helped us in quantifying the problem existing in the manufacturing unit and helped the manufacturer counter the problems.

\section{LITERATURE REVIEW}

In order to understand the DMAIC approach and to implement it for a biscuit manufacturing plant, a detailed literature survey on the topic "Lean Six Sigma implementation on Biscuit Manufacturing" was carried out. Out of 10 papers referred, there were two papers which were found to be very important.

Finsaria Fidiyanti and Novie Susanto ${ }^{[1]}$ carried out a detailed study on the "Analysis of the cause of the defect packaging of capsule products using six sigma: A case study (PT SM)", a company engaged in the field of herbal medicine processing. The work was aimed to manage the amount of defective packaging of capsule products at PT SM. The study was found to be important because the number of defective packaging of capsule products is high and exceeded the maximum limit i.e., $5 \%$ of the total production. In addition, the defective packaging of capsule product could not be reworked and was found to cause loss in terms of time and finance. In this research work, the DMAIC Six Sigma method was used to find out the capability of the production process from the defective packaging of the capsules. Application of the method of Six Sigma DMAIC process eliminated the number of defective products and the Fishbone diagram was used to identify the cause of the defect and the researchers provided the recommendations to improve the production. The data processing using Six Sigma method showed them the value of sigma and the DPMO present in the unit. Using 


\section{International Journal of Engineering Applied Sciences and Technology, 2021 Vol. 6, Issue 2, ISSN No. 2455-2143, Pages 135-143 \\ Published Online June 2021 in IJEAST (http://www.ijeast.com)}

Fishbone diagram the cuases for defectives in packaging of capsules were noted. With the help of the case study outlined in this work, a clear picture on eliminating defects while packaging was achieved and also helped in drawing the Fishbone diagram for manufacturing defects.

Yash N. Jaiswal and Vikram R. Khanzode ${ }^{[2]}$ reported the "Defect Rate Reduction in Biscuit Production Industry using SPC Technique" which explains the variability in a manufacturing process that causes defects in the final product which in turn hampers quality, productivity, profitability and ultimately the customer satisfaction. The main objective of this study was to minimize the defect rate and variability in the final product, i.e., biscuit packaging by using Statistical Process Control (SPC) tools in a biscuit production unit thereby increasing the productivity, profitability and competitive advantage in the market. Several problems in production have been scrutinized by using SPC tools like Pareto analysis, Cause-and-effect diagrams, attribute control charts ( $p$-charts) and process capability analysis. For the sake of this study, several types of defects from two main categories have been considered namely: biscuit defects and packaging defects. On executing the Pareto analysis, three most contributing types of defects were found which when summed up constituted approximately $82 \%$ of the total defects. These defects are Breakage (41\%), Blisters (26\%) and off registration (15\%). For the above-mentioned defects, cause-and-effect diagrams were constructed to pin-point towards the possible root cause of the problems. On the basis of these root causes, certain improvements were recommended. Attribute control charts were plotted and process capability analysis was carried out for the data of proportion of defects collected, before and after the improvement recommendations were implemented by the manufacturer. It was found that, the process of production went from being erratically out of control to being well within the control limits. Hence, the application of SPC tools in regularly monitoring the production processes for defects is extremely effective in improving the productivity and profitability of a production unit.

Apart from this, the work related to biscuit and similar industries was reported by Nitin Upadhye, S. G. Deshmukh and Suresh Garg ${ }^{[3]}$ who worked on the "Lean manufacturing in biscuit manufacturing plant: A case study", D. Manley, Consultant, Duncan Manley Ltd, UK and M. Wilkes, MW Associates, UK explained the "Process and efficiency control in biscuit manufacturing, ${ }^{[4]}$ Ahmad Mukti Almansur, Sukardi and Machfud worked on "Improving performance of biscuit production process through lean six-sigma at PTXYZ" [5], P. D. S. H. Gunawardane and P. T. R. Dabare ${ }^{[6]}$ reported "A signature based approach for quality checking of biscuits", Raquel Nunes Dias, worked on the "Management and optimization of production lines of a food industry"[7]. Fátima Carneiro and Americo Azevedo ${ }^{[8]}$, reported "A six sigma approach applied to the analysis of variability of an industrial process in the field of the food industry", Hsiang-Chin Hung and Ming-Hsien Sung reported their work on "Applying six sigma to manufacturing processes in the food industry to reduce quality cost"[9], and Rui Borges Lopes, Filipa Freitas and Inês Sousa reported the "Application of lean manufacturing tools in the food and beverage industries" ${ }^{[10]}$.

\section{EXPERIMENT AND RESULT}

Define, Measure, Analyze, Improve, Control (DMAIC) is a lean six sigma tool used for process improvement in food, pharmaceutical and other related industries. While some problems have an easy solution which can be solved without following a structured approach, there are some which require a structure to be followed to understand the problems and provide the required solutions; DMAIC is one such approach.

\section{A. The Define Phase}

Define phase involves definition of the problem and our approach lies in providing goals to the manufacturer for waste reduction by analyzing factors that affect the efficiency, downtime, scrap and reusable defects; and to give insights that will aid improve the industry. This phase starts with understanding the processes carried out in the facility. To depict the processes a SIPOC diagram is shown in the Fig. 1. The process starts with receiving raw materials for manufacturing and wrapper materials for packaging from the suppliers. A small sample of each raw material is taken to perform quality tests. Then preparation of dough takes place with the required ingredients and mixes. The dough is then placed in a hopper and is passed through a rotary moulder that places the moulded dough (Biscuits) on the conveyor belt. The conveyor belt then passes through a long oven for the baking process. Then, the baked biscuits are naturally cooled by taking them along a long stretch of conveyor belt. The cooled biscuits are then stacked manually on the stacker. The stacked biscuits are moved by a machine arm and assembled at the packing machine. These biscuits are then packed, after which the packed biscuits are sent for a 'quality check test' before storing in the Finished Goods inventory.

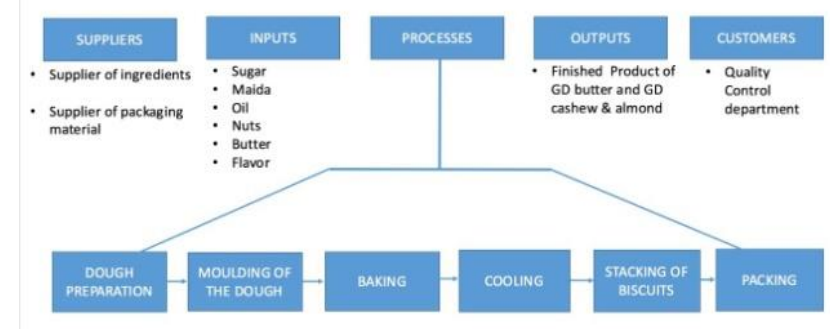

SIPOC DIAGRAM

Fig. 1: SIPOC showing processes involved 


\section{International Journal of Engineering Applied Sciences and Technology, 2021 Vol. 6, Issue 2, ISSN No. 2455-2143, Pages 135-143 \\ Published Online June 2021 in IJEAST (http://www.ijeast.com)}

\section{B. The Measure Phase}

Data required for drawing observations on the downtime and defects occurring at the facility are obtained. After the data filtering process, the data is shown using charts or diagrams for data visualization. Based on the visuals, further examination is done to observe if the data has certain trends or key observations to be noted. This phase helped us decide on the factors to be analyzed in the analyze phase.

1). Measure of Downtime: It was observed that, the form (a manual downtime recording document) earlier used to record downtime lacked structure and did not collect data required to carry out the analysis, as the duration of downtime was unknown. Therefore, a new Form for recording downtime was proposed where 1) Reason for downtime; 2) Duration of downtime and 3) Possible loss in production (in $\mathrm{Kg}$ ) during this duration are all mentioned along with other requirements. The proposed Form was used to record downtime for the months of April and May, 2021. The recorded downtime data was then filtered using MS Excel to find the frequency in which each cause of downtime occurred. This data is then divided into the primary sources: 1). Maintenance; 2). Breakdown and 3) the Production process. The distribution of downtime from each of these sources is shown in Fig 2. In the figure, the first number shown is the duration of downtime in minutes.

Upon observing the downtime data it was observed that, the data was not integral or there was discrepancy in the data. In April there was proper recording of the Oven Band Cleaning downtime (665 min), in May, 2021 it is shown to occur in lesser duration of time (75 $\mathrm{min})$ even though it is a periodic maintenance process. This shows that, there is data inaccuracy. However, since it is a new process for the workers, it was important to train them on the process of recording downtime.
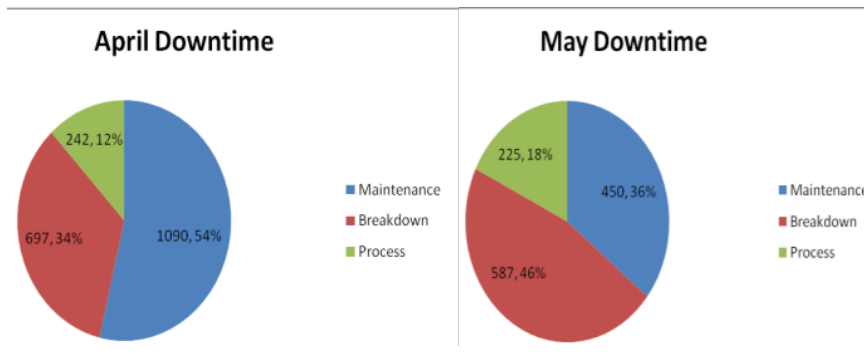

Fig 2: Pie Charts for Downtime

After we decided to work with the data obtained, it was observed that, a large part of the downtime occurred due to maintenance including: 1). Oven Band Cleaning; 2). Mixer Cleaning and 3). Canvas Stitching; and these things were unavoidable.
The second highest downtime is from breakdown of various parts of the conveyor belt line and there was no reason or trend observed on why it happens; also these breakdowns occur randomly. However, it can be accounted to overproduction (!).

$\mathrm{M} / \mathrm{s}$ Britannia requires an average of $75000 \mathrm{Kg}$ biscuits a day, while the Paramount Nutrition Pvt. Ltd., has a record where several days the production is more than $80000 \mathrm{Kg} /$ day. There are a few days in each month where no production takes place because of High Finished Goods Inventory. Overproduction leads to excess load on the machines and higher inventory levels.

The third highest downtime occurred due to the other processes. While most process downtimes are small and nonrecurring, it is seen that, downtime due to Almond/Nut weighing occurred frequently and accumulated to 75 minutes in April and 125 minutes in May 2021. This led to a loss of $4274 \mathrm{~kg}$ in April and $7123 \mathrm{~kg}$ in May 2021 respectively. Since it occurs in small durations, it can be ignored in a day. However, when looking at it in a monthly perspective, there is a big loss. This can be avoided with a simple step of storing weighed almonds/nuts, ready to be mixed instantly.

2). Measure of Defects: Defects data is collected for a period of six months from the month of October 2020 to March 2021. The total defects generated were split into various sections of the production in which they were noticed; to get a better idea on which section has the maximum defects. Hence, to get a better understanding on the causes for it, the various types of defects include were listed out:

1). Oven End; 2). Dirty Bottom; 3). Cooling; 4). MD (metal detected); 5). Stacker; 6). Table End and 7). Packaging.

Workers are stationed across different points of the production line to manually observe the biscuits and remove the defective biscuits from the line. In the oven end there might be biscuits that are over-baked or deformed. Dirty bottom involves presence of the carbon patches or black spots at the bottom of the biscuits. Any biscuits which are found defective along the cooling conveyor are again taken out. MD refers to biscuits that are discarded due to metal detected. A metal detection sensor is placed at the end of the cooling conveyor, and a machine arm discards biscuits that contain metallic impurities. After this, the biscuits are stacked in a line manually on the packing table. Here, sometimes there may be breakage of biscuits. In the table end, a machine arm moves the stacked biscuits towards the packaging machine. Here again, there may be breakage of biscuits due to speed of the machine arm. Packaging defects are related to errors in packaging such as: Loose packaging or wrapper issues.

The amount of defects for each type is summed up for a period of 6 months and subjected to Pareto Chart analysis to get an idea on where the maximum defects are being generated and which section requires higher priority. 

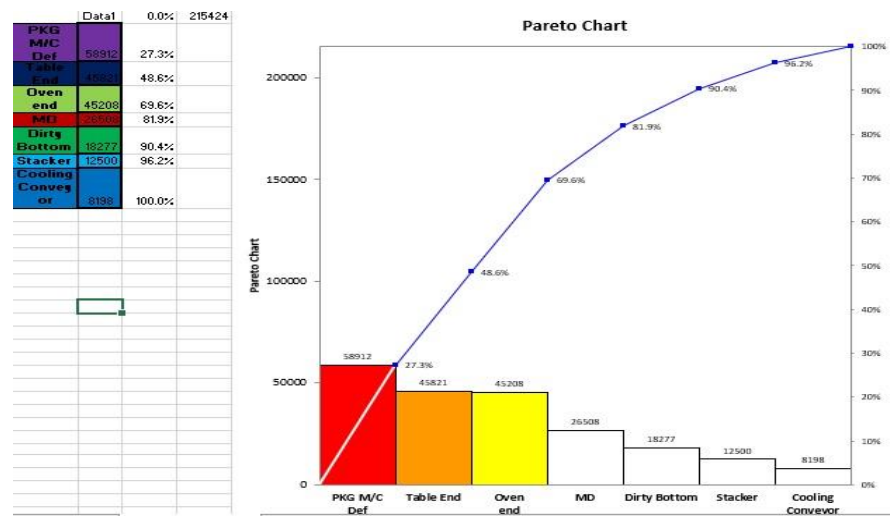

Fig. 3: Pareto chart for defects

From the Pareto Chart (Fig. 3) we can observe that:

1) Maximum defects occur due to packaging which accounts to $27.3 \%$ of the overall defect rate.

2) Packaging, oven end and table end defects cumulatively accounted to $69.6 \%$ of the overall defects.

3) Metal Detected defects sum up to $12.2 \%$ of the overall defect rate.

4) Dirty Bottom, Stacker and Cooling conveyor defects put together accumulate to $19.1 \%$ of the overall defects.

\section{The Analyze Phase}

Thorough analysis was carried out in this phase on the factor/s which required attention from the 'Measure phase'. Since, the Pareto chart (Fig. 3) showed that, packaging defects occur at the highest rate; packaging defects and Manufacturing defects were analyzed separately using control charts to see if the defects are generated in a normal way or if there is an anomaly to be noted. The process sigma levels for Packaging defects and Manufacturing defects were calculated for a months' production so that, it provides us an opportunity to achieve monthly goals for the industry in the Improvement phase.

1). Packaging Analysis: X-bar and R chart (Fig. 4) is used to check if the process is in control, since the defects are spread across two subgroups: Shift A and Shift B, both of equal size, i.e., 8 hours.

While the $\mathrm{R}$ chart shows the range of variation between defects generated in each phase, the $\mathrm{X}$ chart shows the mean amount of defects generated each day across both the shifts through the month. It is seen that the process mean is 203 (Fig. 4, X-Chart), which implies that an average of 203 defects are generated per day through the month. Since, no points are out of the control limits we can say that the process is in control and move onto the process sigma level calculation for packaging defects.

CTQ (Critical to Quality) is a key quality characteristic and is directly related to the specific needs of the customer. In packaging there are 2 types of characteristics that are not acceptable for quality output:

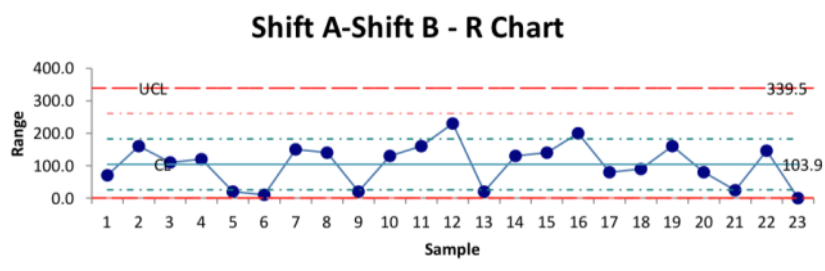

Shift A-Shift B - X Chart

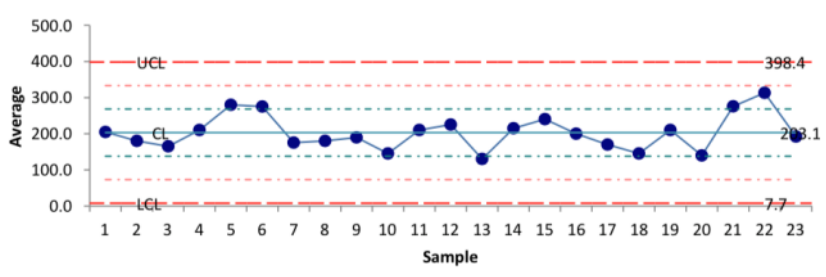

Fig. 4: Control Chart for Packaging Defects

1) Loose packaging.

2) Colour of the packaging not complying to standards.

Determination of process Sigma Level TOP

Total Opportunities $=$ Total product produced $\times$ Number of $\mathrm{CTQ}=1777460.944 \times 2$

$=3554921.89$

DPO (Defect per Opportunities) $=$ Defects/TOP $=9482 /$ $3554921.89=0.00266729$

$\mathrm{DPMO}=\mathrm{DPO} \times 10^{6}=0.00266729 \times 10^{6}=667.29$

SIGMA PERIOD $=$ NORMSINV $((1000000-$

DPMO $) / 1000000)+1.5=$ =NORMSINV $\quad((1000000-$

$2667.29) / 1000000)+1.5=4.29 \sigma$

2). Analyze for Manufacturing: For Manufacturing defects, again X-bar and R chart (Fig. 5) is used to check if the process is in control, since the defects are spread across two subgroups: Shift A and Shift $\mathrm{B}$, both of equal size, i.e., 8 hours.

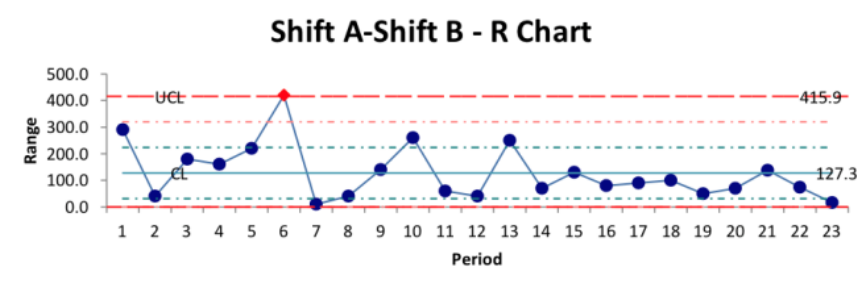

Shift A-Shift B - X Chart

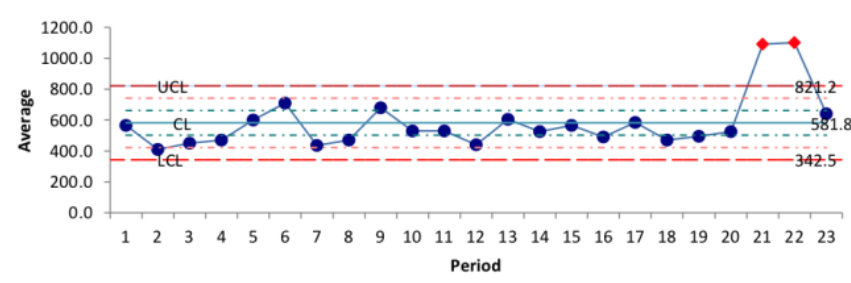

Fig. 5: Control Chart for Manufacturing Defects 


\section{International Journal of Engineering Applied Sciences and Technology, 2021 \\ Vol. 6, Issue 2, ISSN No. 2455-2143, Pages 135-143 \\ Published Online June 2021 in IJEAST (http://www.ijeast.com)}

Here, it is seen that, there are two points which are out of control, at period 21 and 22 (Fig. 5, indicated using red colour). This suggests the presence of an anomaly or a possible special cause for defect increase in this period. Upon further examination by checking the production details, it was seen that, on this day of the month, there was a change-over of production from one variant to the other. Therefore, there was a sudden increase in the number of defects generated. So change-over of production is treated as a possible cause for the increase in the defect rates and solutions to counter it are provided in the next phase of discussion. These two points are then ignored, and the control limits are reset to see if there are any other points acting as an anomaly.

In the improved control chart (Fig. 6), we can see that, there are no points out of the control limit, and the process is in control. We can also see that, the process mean is 533 (XChart), which implies that, an average of 533 defects is generated per day through the month.
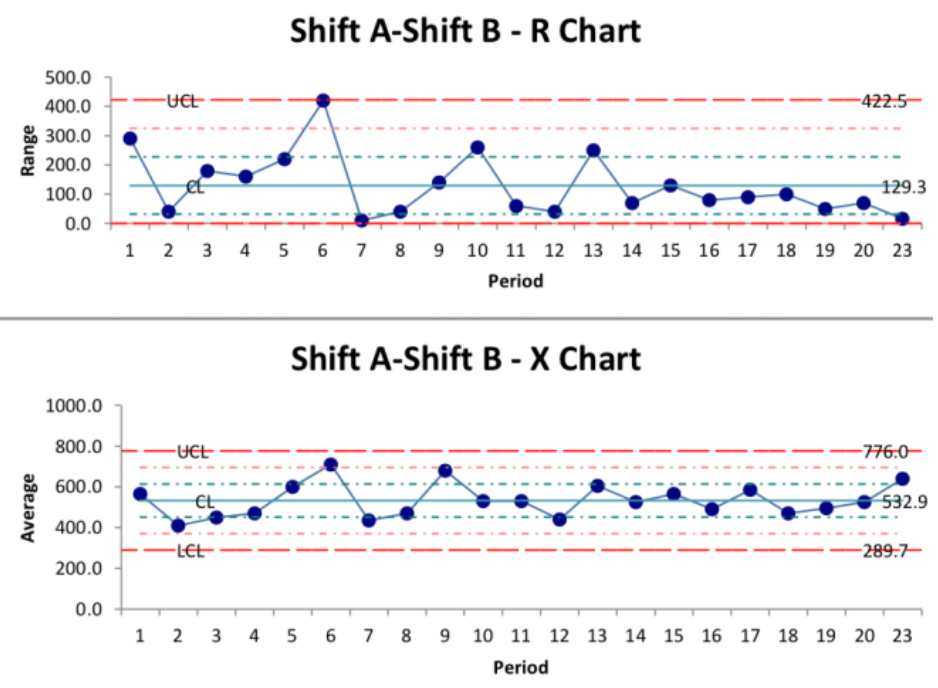

Fig. 6: Improved Control Chart for Manufacturing Defects

We now move on to calculate the process sigma level for manufacturing defects.

CTQ (Critical to Quality) is a key quality characteristic and is directly related to the specific needs of the customer. In manufacturing there are six types of characteristics that are not acceptable for quality output:

1). Deformed Shape.

2). Undesired cracks on surface.

3). Presence of chipped biscuits.

4). Black spots/ Carbon spots.

5). Burnt biscuits.

6). Undesirable blisters bubbles on the surface.
TOP (Total Opportunities) $=$ Total product produced $\times$ Number of CTQ $=1777460.944 \times 6$

$=10664765.66$

DPO (Defect per Opportunities) = D/ TOP = $26974 / 10664765.66=0.00252926$

$\mathrm{DPMO}=\mathrm{DPO} \times 10^{6}=0.00252926 \times 10^{6}=2529.26$

SIGMA PERIOD $=$ NORMSINV $((1000000-$ DPMO $) / 1000000)+1.5=$ NORMSINV $((1000000-$ $2529.26) / 1000000)+1.5=4.30 \sigma$

\section{The Improve Phase}

After finding the defect levels for manufacturing and packaging, monthly goals are given to the manufacturer to reach a defect level of $5 \sigma$. This involves monthly reduction of the defect rates in a step-by-step or systematic manner until the required defect rate is reached. To achieve this causes for the defects are analyzed using a Fishbone diagram. Each cause is then provided with a suggestion for change or improvement. While the manufacturer does an incredible job of meeting the production targets set by

$\mathrm{M} / \mathrm{s}$ Britannia, the defect rates even though small as compared to the production rates, are ignored. Therefore, we wanted to set monthly goals for the manufacturer to reduce their defect rates. This ensures less time spent on rework and the cost incurred due to defects or rework is also reduced.

\section{1). Improvement of Packaging-}

For each month (period), the number of units is taken to be a constant of $1950000 \mathrm{Kg}$. This is because average per day requirement of $\mathrm{M} / \mathrm{s}$ Britannia is for the facility to produce $75000 \mathrm{Kg}$ per day, so this would come up to about 1950000 $\mathrm{Kg}$ during a month. Therefore the defect rate targets to be measured are for every $1950000 \mathrm{Kg}$ of production. Each month the sigma level is increased by a value of 0.1 , until the target of $5 \sigma$ is reached. The respective amount of defects that need to be produced each month or for every $1950000 \mathrm{Kg}$ of production to attain the required level of process sigma is mentioned in the Table 1.

Table 1: Monthly goal for packaging defects

\begin{tabular}{|l|l|l|l|l|l|l|}
\hline Period & $\begin{array}{l}\text { Number } \\
\text { of Units } \\
\text { (In Kgs) }\end{array}$ & $\begin{array}{l}\text { Sigma } \\
\text { Value }\end{array}$ & CTQ & DPMO & TOP & $\begin{array}{l}\text { Number } \\
\text { of } \\
\text { defects } \\
\text { (n Kgs) }\end{array}$ \\
\hline 1 & 1950000 & 4.4 & 2 & 1866 & 3900000 & 7277 \\
\hline 2 & 1950000 & 4.5 & 2 & 1350 & 3900000 & 5265 \\
\hline 3 & 1950000 & 4.6 & 2 & 968 & 3900000 & 3775 \\
\hline 4 & 1950000 & 4.7 & 2 & 687 & 3900000 & 2679 \\
\hline 5 & 1950000 & 4.8 & 2 & 483 & 3900000 & 1884 \\
\hline 6 & 1950000 & 4.9 & 2 & 337 & 3900000 & 1314 \\
\hline 7 & 1950000 & 5 & 2 & 233 & 3900000 & 90 \\
\hline
\end{tabular}




\section{International Journal of Engineering Applied Sciences and Technology, 2021 \\ Vol. 6, Issue 2, ISSN No. 2455-2143, Pages 135-143 \\ Published Online June 2021 in IJEAST (http://www.ijeast.com)}

Increasing in sigma $(\%)=($ Sigma Target-Sigma Baseline)/Sigma Target $\times 100$

$=(5-4.29) / 5 \times 100=14.2 \%$

Decrease in Defects $(\%)=($ Defects Baseline-Defects

Target $) /$ Defects Baseline $\times 100=(9482-909) / 9482 \times 100$

$=90.41 \%$

If the goals/ targets are met, by the end of a 7 month period the manufacturer would witness a decrease in the defect rates by $90.41 \%$.

To achieve these goals, it is important to understand the causes for the defects, and to provide suggestions for improvement to counter these problems. Therefore, we look at the causes for packaging defects using a Fishbone diagram (Fig. 7).

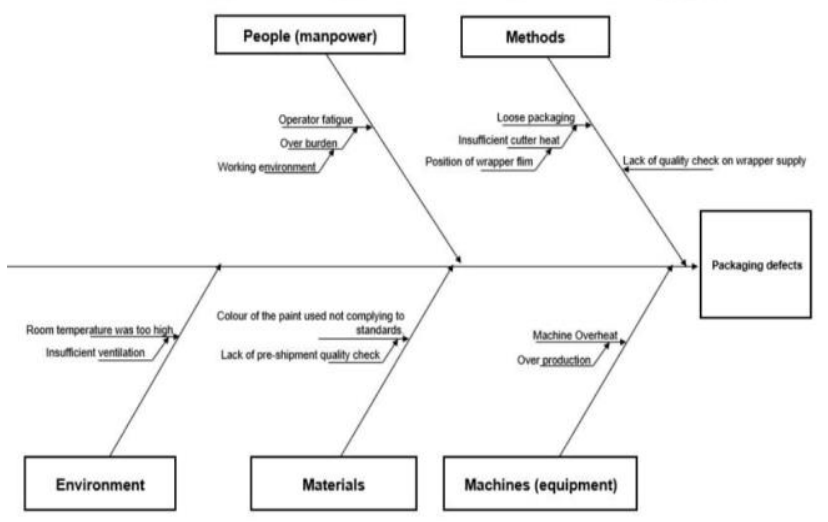

Fig. 7: Fishbone diagram for packaging defects

The Fishbone diagram shows the five primary sources for cause of packaging defects:

1) Manpower; 2) Machinery; 3) Environment; 4) Materials and 5) Methods.

Under each of these sources, the first arrow points to the primary causes:

1). Loose packaging; 2). Operator Fatigue; 3). Machine Overheat; 4). Colour of paint used not complying with standards and 5) Room temperature being too high.

Under the primary causes, arrows point to secondary or root causes that give rise to the primary cause. For each cause a suggestion for improvement is provided in the Table 2. Out of these suggestions the industry can focus on ways that are focused on reducing loose packaging, and to ensure a thorough pre-shipment quality check and complete quality check of the shipment arrived before the production is started for reducing wastage due to problems with the wrapper material.
Table 2: Improvements for packaging defects

\begin{tabular}{|c|c|c|}
\hline Source & Cause & Suggestion \\
\hline \multirow[t]{2}{*}{ Machinery } & $\begin{array}{l}\text { Improper } \\
\text { conveyor speeds }\end{array}$ & $\begin{array}{l}\text { To ensure right conveyor speeds for } \\
\text { the biscuits to get the exact time } \\
\text { required in the baking and cooling } \\
\text { sections. }\end{array}$ \\
\hline & $\begin{array}{l}\text { High Feeder speed } \\
\text { leading } \\
\text { breakage }\end{array}$ & $\begin{array}{l}\text { The high speed of feeder often leads } \\
\text { to breakage of biscuits, to reduce } \\
\text { this, it is important to lower the } \\
\text { machine speed from } 148 \text { to } 130 \\
\text { (packets per min). }\end{array}$ \\
\hline Materials & Dough Mix & $\begin{array}{l}\text { Use of moisture sensors in the } \\
\text { process of mixing to sense extra } \\
\text { moisture. }\end{array}$ \\
\hline \multirow[t]{3}{*}{ Manpower } & $\begin{array}{l}\text { Lack of training } \\
\text { on machine } \\
\text { adjustments }\end{array}$ & $\begin{array}{l}\text { The line engineers need to be } \\
\text { trained on the adjustment required } \\
\text { for conveyor speeds and oven } \\
\text { temperatures for the different } \\
\text { variants and for adjustments } \\
\text { required based on the observed } \\
\text { output. }\end{array}$ \\
\hline & $\begin{array}{l}\text { Rough Stacking of } \\
\text { biscuits }\end{array}$ & $\begin{array}{l}\text { To match the high speed of the } \\
\text { packing machine, it is observed } \\
\text { that, workers have to stack the } \\
\text { biscuits on the table end quickly } \\
\text { often leading to breakage. } \\
\text { Therefore, on reducing the machine } \\
\text { speed workers can handle the } \\
\text { stacking process of biscuits in a } \\
\text { gentler manner reducing the } \\
\text { breakage. }\end{array}$ \\
\hline & Fatigue & $\begin{array}{l}\text { 1). Ensure sufficient lighting } \\
\text { 2). Ensure right room temperature } \\
\text { 3). Cyclic shifting of workers - } \\
\text { Shifting between a heavy task and a } \\
\text { light task every } 30 \text { min. }\end{array}$ \\
\hline \multirow[t]{2}{*}{ Methods } & Change-over & $\begin{array}{l}\text { 1). Ensure thorough cleaning of } \\
\text { mixers before change-over of } \\
\text { variant } \\
\text { 2). Ensure right adjustments of } \\
\text { conveyor speeds and oven } \\
\text { temperature as per requirement of } \\
\text { variant. }\end{array}$ \\
\hline & Over-baking & $\begin{array}{l}\text { 1). Ensure conveyor speeds are set } \\
\text { right so that the biscuits don't spend } \\
\text { more time than required in the oven. } \\
\text { 2). Oven temperature should be } \\
\text { checked at the various points before } \\
\text { start of production. }\end{array}$ \\
\hline
\end{tabular}




\section{International Journal of Engineering Applied Sciences and Technology, 2021 Vol. 6, Issue 2, ISSN No. 2455-2143, Pages 135-143 \\ Published Online June 2021 in IJEAST (http://www.ijeast.com)}

2). Improvement in Manufacturing: Just like setting targets for reducing packaging defects, targets for reducing manufacturing defects are also given. For each month (period), the number of units is taken to be $1950000 \mathrm{Kg}$ which is considered to be constant. This is because average per day requirement of $\mathrm{M} / \mathrm{s}$ Britannia is $75000 \mathrm{Kg}$, this would come up to about $1950000 \mathrm{Kg}$ during a particular month. Therefore, the defect rate targets to be measured are for every $1950000 \mathrm{Kg}$ of production. Each month the sigma level is increased by a value of 0.1 , until the target of $5 \sigma$ is reached. The respective amount of defects which need to be produced each month or for every $1950000 \mathrm{Kg}$ of production to attain the required level of process sigma is mentioned in the Table 3 .

Table 3: Suggestions for manufacturing defects

\begin{tabular}{|c|c|c|c|c|c|c|}
\hline Period & $\begin{array}{c}\text { Number } \\
\text { of Units } \\
\text { (In Kgs) }\end{array}$ & $\begin{array}{c}\text { Sigma } \\
\text { Value }\end{array}$ & CTQ & DPMO & TOP & $\begin{array}{c}\text { Number } \\
\text { of } \\
\text { defects } \\
\text { (In Kgs) }\end{array}$ \\
\hline 1 & 1950000 & 4.4 & 6 & 1866 & 11700000 & 21832 \\
\hline 2 & 1950000 & 4.5 & 6 & 1350 & 11700000 & 15795 \\
\hline 3 & 1950000 & 4.6 & 6 & 968 & 11700000 & 11326 \\
\hline 4 & 1950000 & 4.7 & 6 & 687 & 11700000 & 8038 \\
\hline 5 & 1950000 & 4.8 & 6 & 483 & 11700000 & 5651 \\
\hline 6 & 1950000 & 4.9 & 6 & 337 & 11700000 & 3943 \\
\hline 7 & 1950000 & 5 & 6 & 233 & 11700000 & 2726 \\
\hline
\end{tabular}

Increasing in sigma $(\%)=$

(Sigma Target- Sigma Baseline)/Sigma Target $\times 100=(5-$ $4.30) / 5 \times 100=14 \%$

Decrease in Defects $(\%)=($ Defects Baseline - Defects

Target $) /$ Defects Baseline $\times 10=(26974-2726) / 26974 \times 100$

$=89.89 \%$

Upon reaching the targets through a period of 7 months the manufacturer would observe a reduction in the manufacturing defect rate by $89.89 \%$. To achieve these goals, it is important to understand the causes for the defects, and to provide suggestions for improvement to counter these problems. Therefore, we look at the causes for manufacturing defects using a Fishbone diagram (Fig. 8).

The Fishbone diagram shows the four primary sources for cause of manufacturing defects: 1) the Manpower; 2) the Machinery (equipment); 3) the Material used and 4) the Methods.

Under each of these sources, the first arrow points to the primary causes: 1) Over-baking; 2) Change-over of production; 3) improper conveyor speed; 4) high speed of feeder; 5) lack of training on machine adjustments; 6) rough stacking of biscuits and 7) Lack of moisture detection in the dough mix

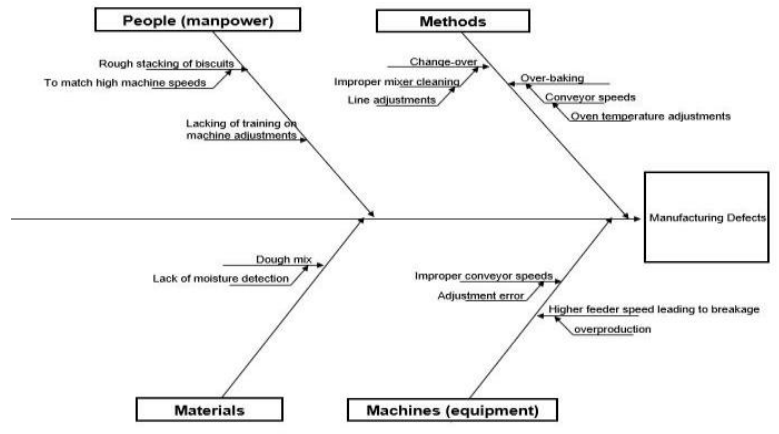

Fig 8: Fishbone diagram for manufacturing defects

Under the primary causes, arrows point to secondary or root causes that give rise to the primary cause. For each cause a suggestion for improvement is provided in the following Table 4. Out of these suggestions the industry can focus on ways that are focused on reducing defects due to over baking and defects due to breakage. This is because through the Pareto chart (Fig. 3) we observed that, the second and third highest defect rates are at the oven end and the table end. In the oven end, defects due to over baking are collected and in the table end, defects due to breakage are observed.

To reduce these defects it is important to ensure that, the conveyor speeds are right so that the dough spends the right amount of time for baking and doesn't undergo baking for longer times than required. The line engineers should be trained and knowledgeable regarding the oven temperature and machine adjustments for each biscuit variant. To reduce defects due to breakage it is important to reduce the speed of the feeder arm which moves the biscuits from the table end to the packaging machine. When speed of the feeder arm is reduced, workers at the stacker end can handle the biscuits more easily, thereby reducing breakage at the stacker end as well. The suggestions for improvements to reduce manufacturing defects are presented in the Table 4.

Table 4: Improvements for manufacturing defects

\begin{tabular}{|l|l|l|}
\hline Source & Cause & Suggestions \\
\hline Material & $\begin{array}{l}\text { Color of the paint } \\
\text { used not complying } \\
\text { with standards }\end{array}$ & $\begin{array}{l}\text { 1). Sending the supplier a QC } \\
\text { checklist which includes clear } \\
\text { packaging standards to be met } \\
\text { before shipping. } \\
\text { 2). Conduct Quality Check for the } \\
\text { entire wrapper supply before } \\
\text { packaging. }\end{array}$ \\
\hline Method & $\begin{array}{l}\text { 1) Ensure cutter heat is } \\
\text { maintained for perfect sealing of } \\
\text { packets with regular checks on } \\
\text { cutter heat. } \\
\text { 2). Ensure film is centered on the } \\
\text { spindle. } \\
\text { 3). Ensure Rollers are spinning }\end{array}$ \\
\hline
\end{tabular}




\section{International Journal of Engineering Applied Sciences and Technology, 2021 \\ Vol. 6, Issue 2, ISSN No. 2455-2143, Pages 135-143 \\ Published Online June 2021 in IJEAST (http://www.ijeast.com)}

\begin{tabular}{|l|l|l|}
\hline & \multicolumn{1}{|c|}{} & freely. \\
\cline { 2 - 3 } & $\begin{array}{l}\text { Lack of Quality } \\
\text { Check on Wrapper } \\
\text { Supply }\end{array}$ & $\begin{array}{l}\text { Conduct Quality Check for the } \\
\text { entire wrapper supply before } \\
\text { packaging. }\end{array}$ \\
\hline Machine & Machine Overheat & $\begin{array}{l}\text { 1). Avoid overproduction. } \\
\text { 2). Regular heat checks. }\end{array}$ \\
\hline Manpower & Operator Fatigue & $\begin{array}{l}\text { 1). Ensure sufficient lighting. } \\
\text { 2). Ensure right room } \\
\text { temperature. }\end{array}$ \\
& $\begin{array}{l}\text { 3). Cyclic shifting of workers- } \\
\text { Shifting between a heavy task and } \\
\text { a light task every 30 min. }\end{array}$ \\
\hline Environment & $\begin{array}{l}\text { Room temperature } \\
\text { too hot }\end{array}$ & $\begin{array}{l}\text { Provide fans all over the plant } \\
\text { and ensure sufficient ventilation. }\end{array}$ \\
\hline
\end{tabular}

\section{E. The Control Phase}

This phase focuses on controlling the results obtained, and to systematically compare the results obtained with respect to the target value.

After providing the goals, suggestions and insights it is up to the manufacturer to consider our input and make the changes they feel is required to achieve the monthly goals set for reducing defect rates. Upon reaching the goal set, it is essential for the manufacturer to then maintain the new system established for keeping the defect rate under control at the new level that is reached. This would then see the functioning at $5 \sigma$ level with respect to both packaging and manufacturing defects produced.

\section{RESULTS AND DISCUSSION}

In the measure phase of the present work, downtime data is first observed. Upon finding out this, the existing Form which lacked the structure was not enough to maintain downtime, a new Form was proposed where: 1). Reason for downtime; 2). Duration of downtime and 3). Production loss in $\mathrm{Kg}$ due to downtime is then measured. This Form was used to record data for April and May 2021, and downtime data was obtained for these 2 months. It was observed that, downtime data collected was inaccurate and not appropriate to carry out analysis as it would offer inconclusive results. Training was required on personnel to record the downtime in the proposed Form. However, it was seen that, the highest downtime occurred due to maintenance procedures which were unavoidable. The second highest downtime occurred due to breakdown, however, the breakdowns occur in different parts of the production line at random and there was no trend observed. The third highest downtime occurred due to processes involved, however these are small and nonrecurring.

Defects data was available for different sections in which the defects are generated. This proved valuable in assessing the section in which the most defects are generated. Using the Pareto Chart we were able to notice that, the highest numbers of defects were generated in the packaging section which comprised of $27.3 \%$ of the overall defect rate. This was followed by table end and oven end defects. Together these three defects alone accounted to $69.6 \%$ of the overall defect rate. Therefore, the process sigma levels for packaging and manufacturing were calculated separately. Packaging defects sigma level was found to be $4.29 \sigma$ and that of manufacturing defects was found to be $4.3 \sigma$. To reduce the defect rates in the organization, monthly goals were given to the manufacturer to reach a sigma level of $5 \sigma$ for both packaging and manufacturing. The causes for the defects were then analyzed and suggestions for improvement were provided, with a focus to reduce the defects in the packaging, table end and oven end sections.

\section{CONCLUSIONS AND OUTCOME}

While the manufacturer does an impressive job of meeting the production targets, it is seen that, the defect rates are ignored or in other words the possibility to reduce defect rates were not treated as a priority. It is important for the manufacturer to have set goals in any domain to excel further. Therefore, we offered the manufacturer to set monthly goals to be achieved over a period of 7 months which would see the manufacturer reduce the defect rate of Packaging by $90.41 \%$ and that of Manufacturing by $89.89 \%$ by reaching a $5 \sigma$ process level in both manufacturing and packaging.

\section{FUTURE SCOPE}

Recording of downtime is very important which needs to be carried out properly, as it gives the manufacturer a better idea on the types and duration of downtime causes. Downtime is basically a loss of precious time for manufacturing, so in industries such as biscuit manufacturing industry where the amount of output generated per minute is high, even a few min of downtime is linked to a big loss in production. Therefore, only by recording and analyzing the downtime, there can be attempts to tackle the losses. Since, it proved that, manual recording of downtime was not efficient, implementation of an automated downtime tracking system would help the manufacturer in getting valuable information related to downtime.

To show the necessity of reducing the defect rates, a Cost Benefit Analysis should be carried out to indicate the benefits or the reduction in cost incurred by meeting the defect rate targets. Commercial data such as cost incurred by the company could not be disclosed to us due to technical/confidentiality reasons. However, carrying out this analysis would help in emphasizing the need for reducing defects. 


\section{International Journal of Engineering Applied Sciences and Technology, 2021 \\ Vol. 6, Issue 2, ISSN No. 2455-2143, Pages 135-143 \\ Published Online June 2021 in IJEAST (http://www.ijeast.com)}

\section{ACKNOWLEDGEMENTS}

The authors wholeheartedly thank M/s Paramount Nutrition Pvt. Ltd., for giving us an opportunity and freedom to carry out the present work in their unit and for adopting the recommendations suggested by us for improving the production. We also thank Mr. B. R. Deepak, Production Manager of M/s Paramount Nutrition Pvt. Ltd. for guiding us to complete this work satisfactorily and The Principal Dr. K. $\mathrm{N}$. Subramanya, R V College of Engineering and its Management for their encouragement during the entire period of this study.

\section{REFERENCES}

[1]. F. Fidiyanti, N. Susanto, "Analysis of the cause of the defect packaging of capsule products using six sigma: A case study (PT SM)", SHS Web of Conferences, 49, 02011, ICES 2018, pp. 1-7, 2018.

[2]. Y. N. Jaiswal, V. R. Khanzode, "Defect Rate Reduction in Biscuit Production Industry using SPC Technique", Int. J. Engineering Research \& Technology (ISSN: 2278-0181), Vol. 9 (11), pp. 578-584, 2020.

[3]. N. Upadhye, S. G. Deshmukh, S. Garg, "Lean manufacturing in biscuit manufacturing plant: A case study", Int. J. Advanced Operations Management, Vol. 2, Nos. 1/2, pp. 108-134, 2010.

[4]. D. Manley, Consultant, Duncan Manley Ltd, UK and M. Wilkes, MW Associates, UK, "Process and efficiency control in biscuit manufacture", Published by Woodhead Publishing Limited, 2011.

[5]. A. M. Almansur, Sukardi, Machfud, "Improving performance of biscuit production process through lean sixsigma at PT XYZ", Indonesian J. Business and Entrep., (pISSN: 2407-5434, e-ISSN: 2407-7321), DOI: 10.17358/IJBE.3.2.77, pp 77-88, 2017.

[6]. P. D. S. H. Gunawardane, P. T. R. Dabare, "A Signature Based Approach for Quality Checking of Biscuits", $8^{\text {th }}$ International Conference on Ubi-Media Computing (UMEDIA): 092-097, 2015.

[7]. R. N. Dias, "Management and optimization of production lines of a food industry", TECNICO LISBOA, pp. 1-8, 2017.

[8]. F. Carneiro, A. Azevedo, "A Six Sigma Approach Applied to the Analysis of Variability of an Industrial Process in the Field of the Food Industry", IEEE 2017, IEEE International Conference on Industrial Engineering and
Engineering Management (IEEM) - Singapore, DOI: 10.1109/IEEM.2017.8290177, pp. 1672-1679, 2017.

[9]. H-C. Hung, M-H. Sung, "Applying six sigma to manufacturing processes in the food industry to reduce quality cost", DOI: 10.5897/SRE10.823, Scientific Research and Essays (ISSN 1992-2248), Vol. 6 (3), pp. 580-591, 2011.

[10]. R. B. Lopes, F. Freitas, I. Sousa, "Application of Lean Manufacturing Tools in the Food and Beverage Industries", $J$. Technology Management \& Innovation (ISSN: 0718-2724), Vol. 10 (3), pp. 120-129, 2015. 